\title{
Long-term Enhancement Produced by Activity-dependent Modulation of Aplysia Sensory Neurons ${ }^{1}$
}

\author{
EDGAR T. WALTERS ${ }^{2}$ AND JOHN H. BYRNE \\ Department of Physiology and Cell Biology, University of Texas Medical School at Houston, Houston, Texas 77025
}

\begin{abstract}
We have investigated long-lasting enhancement of signaling effectiveness in the tail sensory neurons of Aplysia using both intracellular and extracellular stimulation. The pairing of high frequency homosynaptic activation with heterosynaptic modulation produced significantly greater enhancement of monosynaptic connections to identified motor neurons than did homosynaptic activity, heterosynaptic modulation, or test stimuli alone. Enhancement of the monosynaptic excitatory postsynaptic potential produced by pairing persisted for at least $4 \mathrm{hr}$, and the kinetics of decay of this potentiation indicated a time constant of about $5 \mathrm{hr}$. Although unpaired stimulation produced much weaker enhancement, both homosynaptic activity and heterosynaptic modulation alone produced enhancement lasting more than $\mathbf{9 0}$ min. The results are consistent with the possibility that intrinsic electrical activity can amplify the modulatory effects of a paired extrinsic chemical signal to produce long-term changes in synaptic strength. Paired stimulation also produced a relative enhancement of the excitability of the sensory neuron soma as judged by changes in action potential threshold. The lack of generalized changes in the postsynaptic cell and the observation of pairing-induced long-term changes in action potential threshold in the presynaptic cell soma suggest that longterm enhancement produced by pairing has a presynaptic locus in this system. Since pairing-specific enhancement can encode associations between sensory and motivational events in these cells, this form of plasticity may function as a form of associative memory. Similarities between long-term paired enhancement in this system and associative longterm potentiation in other systems suggest that activitydependent neuromodulation might be involved in cellular memory in other systems as well.
\end{abstract}

Persistent potentiation of postsynaptic responses following brief, high frequency activation of presynaptic axon bundles was first demonstrated in the hippocampus (Bliss and Lomo, 1973) but has now been described in other parts of the mammalian central nervous system (Lee, 1982; Gerren and Weinberger, 1983; Racine et al., 1983), in the peripheral nervous system (Brown and McAfee, 1982), and in invertebrate preparations (Baxter and Brown, 1983). Such

Received April 6, 1984; Revised August 30, 1984; Accepted August 31, 1984

\footnotetext{
${ }^{1}$ This work was supported by a National Institutes of Health Biomedical Research Grant to E. T. W. and by National Institutes of Health Grant NS 19895 to J. H. B. We thank T. Abrams, T. Crow, and D. Johnston for their helpful comments on an earlier draft of this paper.

${ }^{2}$ To whom correspondence should be addressed.
}

long-term synaptic enhancement, lasting at least several hours, has received growing attention because of the possibility that it is related to natural mechanisms of memory and learning (e.g., Douglas and Goddard, 1975). Although neither the cellular mechanisms nor the functions of these long-term synaptic changes have yet been determined conclusively, speculation along both lines has been stimulated recently by demonstrations of "cooperative" and "associative" influences on long-term potentiation (LTP) in the hippocampus (McNaughton et al., 1978; Levy and Steward, 1979; Robinson and Racine, 1982; Barrionuevo and Brown, 1983; Lee, 1983; also, see "Discussion"). At the same time, both associative learning (Walters et al., 1979, 1981; Carew et al., 1981, 1983) and the associative conditioning of individual neurons (Walters and Byrne, 1983a; Hawkins et al., 1983) have recently been demonstrated in the convenient molluscan preparation, Aplysia, but procedures analogous to those used to study hippocampal LTP have not been examined in this animal. Because of the possibility that LTP and long-term memory involve general mechanisms of associative information storage, we wanted to determine whether well defined synaptic connections in Aplysia that are known to be associatively modifiable can exhibit long-term enhancement under conditions similar to those used to produce LTP in other preparations. We were particularly interested in the possibility that a mechanism for the associative conditioning of single cells-activity-dependent neuromodulation (Walters and Byrne, 1983a; see also Hawkins et al, 1983) - might contribute to long-term enhancement.

Below we describe an intracellular analysis of long-term enhancement of synaptic strength and of the excitability of the sensory neuron soma in Aplysia. Our results suggest that activity-dependent neuromodulation is a mechanism of long-term enhancement and that this enhancement can be a form of associative information storage. Some of these results have been described earlier in abstract form (Walters and Byrne, 1983c).

\section{Materials and Methods}

Experiments were performed on Aplysia californica (150 to $350 \mathrm{gm}$ ) supplied by Marine Specimens Unlimited (Pacific Palisades, CA). Each animal was anesthetized by injection of a volume of isotonic $\mathrm{MgCl}_{2}$ equal to $50 \%$ of its weight, and the left pedal-pleural ganglia were removed and placed in a dissection medium consisting of equal parts of isotonic $\mathrm{MgCl}_{2}$ and artificial seawater (Instant Ocean). Both ganglia were then desheathed surgically, and branches of peripheral nerves innervating the left posterior part of the body were drawn into suction electrodes for nerve stimulation. These branches included all of the major branches of $L p 9$ and, in some cases, the major posterior branch of LP8 (see Kandel, 1979, for nomenclature and JahanParwar and Fredman, 1978, for fields of innervation).

The isolated pedal-pleural ganglia preparation was then superfused at a constant rate with artificial seawater $\left(21\right.$ to $\left.23^{\circ} \mathrm{C}\right)$ for the duration of the experiment. After $45 \mathrm{~min}$, one of the three identified tail motor neurons, LP5, LP6, or LP7 (Walters et al., 1983a), was impaled with two electrodes filled with $3 \mathrm{M}$ potassium acetate. One electrode monitored voltage and the other passed current to hyperpolarize the motor neuron about $30 \mathrm{mV}$ below action potential threshold during the testing and training procedures to allow measurement of EPSP amplitude in the absence of spikes. In experiments 
in which the monosynaptic EPSP from individual sensory neurons was measured, two to four sensory neurons in the pleural VC cluster (Walters et al., 1983a) were impaled with single microelectrodes following impalement of the motor neuron.

\section{Testing procedures}

Responses to stimulation of two different nerves (Fig. 1A) were tested by applying 2-msec pulses through polyethylene suction electrodes containing the $\mathrm{MgCl}_{2}$-artificial seawater dissection medium. This electrode solution was used to avoid activation of the nerve by the initial trauma of suction into the electrode tube. The intensity of nerve stimulation necessary to reach threshold for a complex EPSP response in the motor neuron was determined by applying successively stronger test stimuli (through a W-P Instruments model $1850 \mathrm{~A}$ stimulus isolator) at 5-sec intervals. The nerve test intensity was then increased 50 to $150 \%$ above threshold to obtain a "moderate intensity" response; i.e., a complex EPSP amplitude between 15 and $25 \mathrm{mV}$. Pilot experiments indicated that this intensity was weak enough to allow measur-

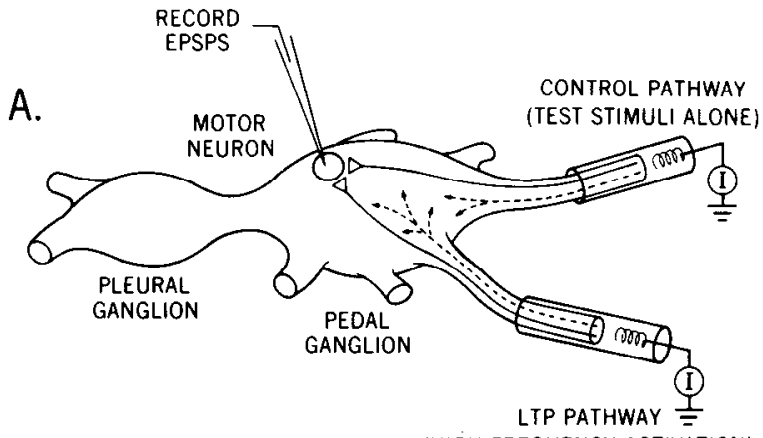

B.

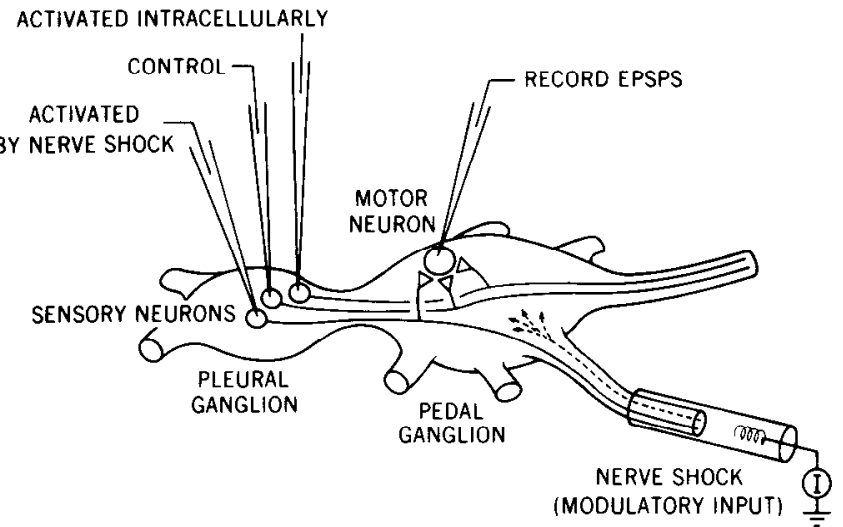

Figure 1. In vitro ganglia preparations used to examine long-term enhance ment. The dashed lines indicate neuromodulatory effects (heterosynaptic facilitation) implicated in previous studies (Walters and Byrne, 1983a; Walters et al., 1983a). It is not yet known whether the cells mediating the modulatory effects are activated synaptically or directly by nerve shock. $A$, Plasticity of the complex EPSP. Test EPSPs containing mono- and polysynaptic components from brief stimulation of two nerves (via suction electrodes) were recorded in a common tail motor neuron in the pedal ganglion. One nerve was randomly chosen to receive the high frequency activation sequence (nerve LTP training). A second nerve was used as a control pathway. $B$, Plasticity of the monosynaptic EPSP. Tail sensory neurons in the pleural ganglion were impaled and used to elicit monosynaptic test EPSPs in a common tail motor neuron in the pedal ganglion. The effects of high frequency homosynaptic activation (Homo) and test stimuli alone (test-alone control) were examined concurrently in the same preparations. Homosynaptic activation was produced by high frequency intracellular activation of a single tail sensory neuron soma. Homosynaptic activation paired with heterosynaptic modulation (paired) and heterosynaptic modulation from the nerve shock alone (hetero controi) were examined concurrently in other preparations. The paired sensory neuron activity was produced either by direct intracellular stimulation of the soma (paired-soma) or by stimulation of its axon by the nerve shock (paired-axon). In paired-soma stimulation the sensory neuron had its axon in a nerve other than the one receiving nerve shock. able facilitation of the complex EPSP from nerve stimulation before action potential threshold in the motor neuron was reached. Testing began at least 15 min after setting the test intensity and consisted of the delivery of single pulses to each nerve at 10-min intervals. On each test the nerve stimuli were separated by $10 \mathrm{sec}$. The brief, high frequency training sequence (see below) occurred $30 \mathrm{sec}$ after the second of two base line tests. After training, testing then continued at 10-min intervals for $2 \mathrm{hr}$. In some cases isolated tests were also delivered 3,4 , and $10 \mathrm{hr}$ after training.

To test monosynaptic EPSPs from individual tail sensory neurons (Fig. $1 B$ ), brief (10- to $20-\mathrm{msec})$ depolarizing pulses were injected through the electrode in each soma to elicit a single action potential at 10 -min intervals before and for at least $2 \mathrm{hr}$ after training. Some cells were also tested 3,4 , and $5 \mathrm{hr}$ after training. On each test, stimuli to different sensory neurons were separated by 5 to $10 \mathrm{sec}$. In 22 cells in eight preparations, threshold for sensory neuron action potential generation was determined in each test, using a variant of this soma stimulation procedure. Depolarizing current pulses (10 msec) were applied at about 2-sec intervals, beginning at $0.5 \mathrm{nA}$ and proceeding in $0.1-n A$ increments until threshold was reached. Threshold was defined as the minimum current necessary to elicit an action potential. Only a single action potential in each sensory neuron was generated in each test

\section{Training procedures}

Each group is identified operationally by the training procedure it received. In the remainder of the paper we use the abbreviation (in parentheses below) of this procedural name.

\section{Complex EPSP}

" $L T P$ " procedure (nerve LTP). This procedure was named for its formal resemblance to procedures used to produce LTP in heterogeneous mammalian pathways (e.g., Levy and Steward, 1983; Berger, 1984). Although operationally similar, "LTP" in our preparation and LTP in mammalian systems do not necessarily have similar mechanisms. One of two peripheral test nerves (Fig. 1A) was randomly selected and given a high frequency sequence of the pulses described above for testing. In most cases the two nerves were a branch of $L p 8$ and a branch of Lp9. In a few cases two branches of Lp9 were compared. The 45-sec training sequence consisted of 10 trains of 10 pulses $(25 \mathrm{~Hz})$ delivered at 5 -sec intervals (this same pattern was also used for intracellular training procedures-see below). Each of the nerves selected innervated part of the posterior half of the body and contained axons from some (but not all) of the tail sensory neurons. Although the entire sequence was designed to resemble LTP procedures in mammals, the duration and frequency of each train in the sequence were selected to match the bursts observed in tail sensory neurons in response to moderate intensity cutaneous stimulation (Walters et al., 1983a). Such bursts can produce short-term post-tetanic potentiation (PTP) in these synapses (Walters and Byrne, 1984).

Test stimuli alone (Control). As a control against which to measure potentiation in the nerve LTP group, we applied test stimuli alone (no high frequency training sequence) to a second nerve in each nerve LTP preparation (Fig. 1A)

\section{Monosynaptic EPSP}

Test stimuli alone (test-alone). Intracellular test stimuli alone were delivered to one or two sensory neurons in the same preparation in which homosynaptic soma activation training (see below) was applied to another sensory neuron (Figs. $1 B$ and 3 ).

Homosynaptic soma activation (Homo). The same high frequency pattern of stimulation (100 pulses total) delivered to the nerve was delivered intracellularly to a single sensory neuron soma, except that each pulse was 10 rather than $2 \mathrm{msec}$ long. No nerve shock was applied (Figs. $1 B$ and 3 ).

Heterosynaptic nerve stimulation (Hetero). The purely heterosynaptic effects of neve shock were monitored by recording monosynaptic connections from intracellularly monitored sensory neurons (Fig. $1 B$ ) that were not activated either intracellularly or by the high frequency nerve shock (presumably because their axons were in other nerves) in preparations used for paired training (see below and Fig. 6). The nerve shock was the same as that used in the nerve LTP procedure (above).

Paired homosynaptic soma activation and heterosynaptic stimulation (paired-soma). The Homo training sequence and the Hetero training sequence were applied simultaneously. Thus, a single sensory neuron soma that did not have an axon in the stimulated nerve received 10 high frequency trains (of ten 10-msec intracellular depolarizing puises each) simultaneously with the delivery of the nerve LTP training sequence of 2-msec extracellular pulses applied to the nerve (Figs. $1 B$ and 6). 
Paired homosynaptic axon activation and heterosynaptic nerve stimula tion (paired-axon). The nerve shock used to produce Hetero training was itself used to activate axons of intracellularly recorded sensory neurons (Figs. $1 B$ and 9 ).

Paired homosynaptic activation and heterosynaptic nerve stimulation (paired). For some analyses (Figs. 11 and 12) cells from the paired-soma and paired-axon groups were combined into a single paired group.

\section{Data analysis}

EPSPs were normalized to the mean of the two base line tests. If more than one cell was examined simultaneously within a training group in a given preparation, the normalized responses from each cell were averaged on each test and the average responses were analyzed. Unless otherwise indicated, a $t$ test for correlated means was used (in particular, when members of two training groups had responses measured in the same motor neuron concurrently in each preparation, or when responses were compared to base line levels). For comparison to base line raw data rather than normalized data were used. Discrepancies between the number $(N)$, indicated in the figure legend and the degrees of freedom reported in some paired comparisons appear because the figures represent all of the data, whereas the correlated statistics could only be performed on animals containing members of both groups being compared. For uncorrelated comparisons a $t$ test for independent groups, an analysis of variance, or (if cutoffs were involved) a Mann-Whitney $U$ test was performed on the normalized data. One-tailed tests were made (except where noted) on the basis of preliminary pilot experiments; $p<0.05$ was considered significant.

\section{Results}

Effects of an LTP procedure on the complex EPSP. Because LTP of synapses in the mammalian nervous system has been produced by stimulating heterogeneous groups of presynaptic fibers, we were first curious to learn whether analogous stimulation of a heterogeneous fiber bundle in Aplysia would also produce long-term synaptic enhancement. Two branches of nerves innervating the posterior half of the animal were tested with single pulses at 10 -min intervals for $130 \mathrm{~min}$, and the resulting complex (mono- and polysynaptic) EPSPs were recorded in a tail motor neuron. After the second test, one of the nerve branches was given a $45-\mathrm{sec}$ high frequency training sequence (see "Materials and Methods"). Figure $2 A$ illustrates the effects of this training on test responses of the tetanized (LTP) and control pathways. The LTP pathway displayed facilitated test responses for as long as the preparation was examined (more than $10 \mathrm{hr}$ in this case; following the 2-hr test the tests were delivered at 3,4 , and $10 \mathrm{hr}$ ). By contrast, the control pathway showed transient facilitation with the responses falling below base line within an hour. Figure $2 B$ shows the pooled results from eight animals. Two hours after the LTP training sequence the tetanized nerve produced significantly greater test responses than did the control nerve $\left(t_{7}=4.2\right.$; $p<0.005)$. In five preparations the cells were held for at least $3 \mathrm{hr}$ after training, and at this point there was still significant relative potentiation in the tetanized pathway $\left(t_{4}=4.1 ; p<0.01\right)$.

Effects of homosynaptic activation on the monosynaptic EPSP. Having found long-lasting synaptic potentiation in Aplysia, resembling in magnitude and duration various examples of LTP of synapses in other preparations (see "Discussion"), we next sought to characterize the underlying mechanisms. We had selected the particular nerves for studying the complex EPSP in part because they contain axons of an identified group of tail sensory neurons that make monosynaptic connections to the monitored motor neurons (Walters et al., 1983a). Thus, the observed potentiation of nerve-evoked test responses could have involved enhancement of these monosynaptic connections. We first asked whether high frequency homosynaptic activity was sufficient to produce long-term enhancement. We applied intracellular test pulses to individual sensory neurons at 10-min intervals to elicit single action potentials and test EPSPs. After two tests, one sensory neuron was selected randomly to receive the high frequency homosynaptic activation sequence (Fig. 3; see also Homo procedure under "Materials and Methods"). One or two other sensory neurons served as controls for the effects of simply applying test stimuli alone (test responses not

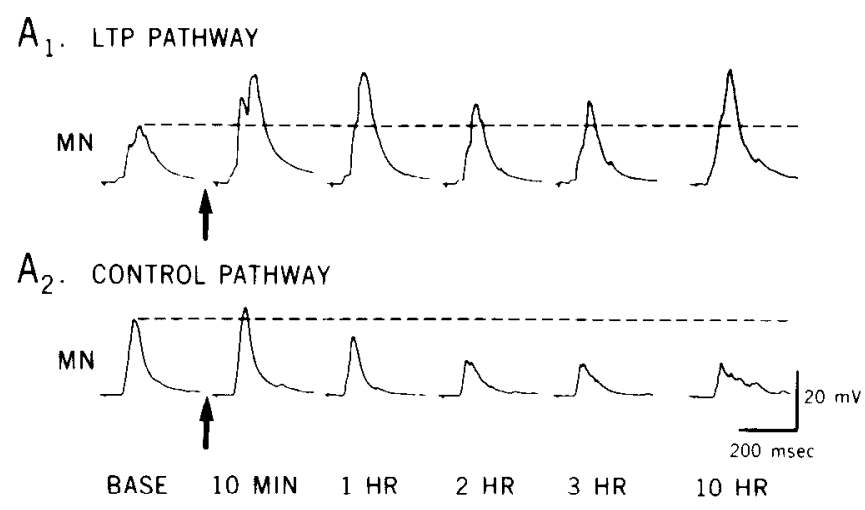

B

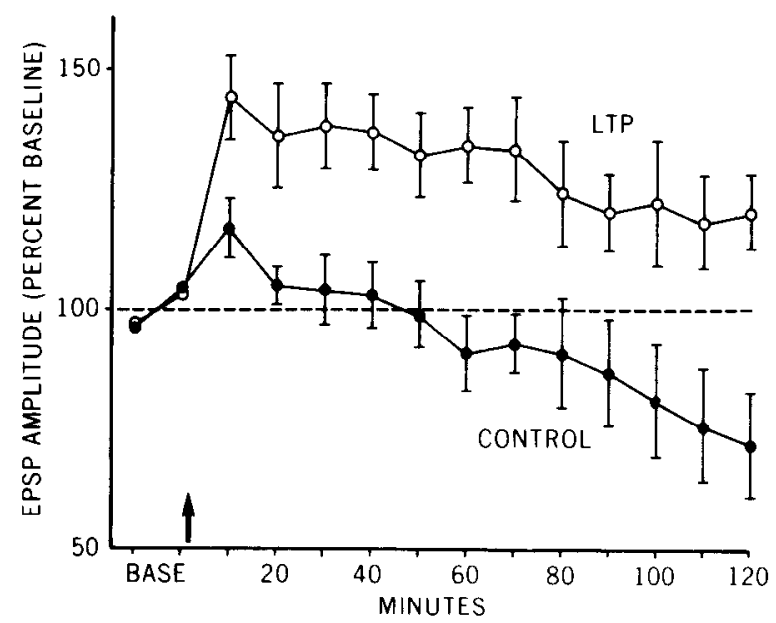

Figure 2. Long-term enhancement of the complex EPSP in a tail motor neuron $(M N)$. A, Examples of test EPSPs from nerve shock. At the arrows, one nerve received high frequency stimulation designed to resemble LTP training procedures in other preparations. $A_{1}$ : The tetanized LTP pathway showed a persistent facilitation that remained for $10 \mathrm{hr}$, as long as the preparation could be tested. After $2 \mathrm{hr}$ of testing the test intervals were increased (see "Materials and Methods"). $A_{2}$ : The control pathway showed a transient facilitation relative to the base line that persisted for less than $1 \mathrm{hr}$. $B$, Mean $( \pm$ SEM) complex EPSP amplitudes for cells held at least $2 \mathrm{hr}(\mathrm{N}=$ 8). Tetanization of the LTP pathway occurred after two base line tests (arrow).

shown in Fig. 3). Unlike the paired training (see below), this Homo training sequence did not elicit observable polysynaptic excitatory input to the motor neuron or hyperpolarizing responses in the inactive sensory neurons (cf. Figs. 3 and 6)

Monosynaptic test responses of the sensory neurons given high frequency homosynaptic activation or test stimuli alone are illustrated in Figure 4. The activated cell showed enhanced synaptic responses that were prominent shortly after training, but the EPSPS then declined with continued testing. By contrast, the control cell only showed synaptic depression that is characteristic of tail sensory neurons during low frequency stimulation (Walters et al., 1983a).

Pooled results from 11 animals are shown in Figure 5. Test responses for each group were measured in the same motor neuron in each preparation. Following the large initial enhancement in the Homo group, the responses of the two groups gradually converged with continued testing. Ninety minutes after training, the Homo group showed significant enhancement compared to the test-alone group $\left(t_{10}=1.99, p<0.05\right)$. On the 100- and 110 -min tests there was no significant difference between these groups $\left(t_{10}=1.35\right.$ and 1.02 , respectively), but on the 120 -min test the Homo group showed a small but significant enhancement compared to the test-alone group's responses $\left(t_{10}=1.90, p<0.05\right)$. Thus, our statistical analysis suggests that the possible long-term contribution of homo- 
MN

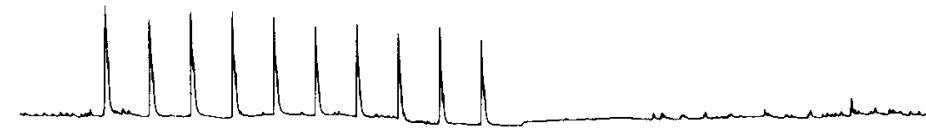

SN 1

SN 2

SN 3

(ACTIVATED)

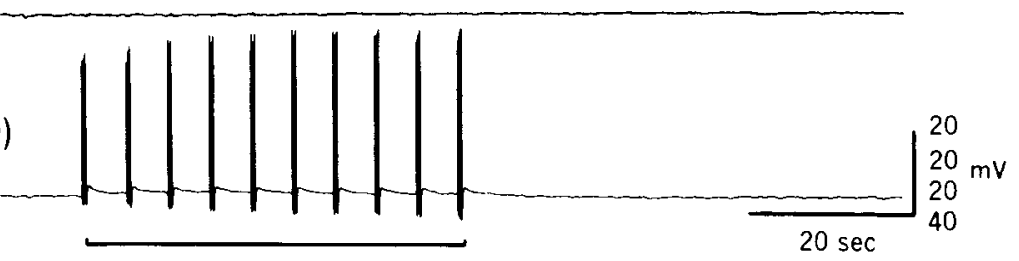

Figure 3. Homosynaptic activation (Homo) training procedure. Recordings from a tail motor neuron $(M N)$ and three tail sensory neurons (SN1 to SN3) during the homosynaptic activation sequence applied to SN3. The training sequence consisted of ten $400-\mathrm{msec}$ bursts (each $25 \mathrm{~Hz}$ ) applied at 5-sec intervals. Note the apparent lack of polysynaptic excitation of the motor neuron or hyperpolarizing responses in the sensory neurons (cf. Fig. 6).

\section{HOMOSYNAPTIC ACTIVATION SEQUENCE}

\section{A. HOMOSYNAPTIC ACTIVATION}

MN

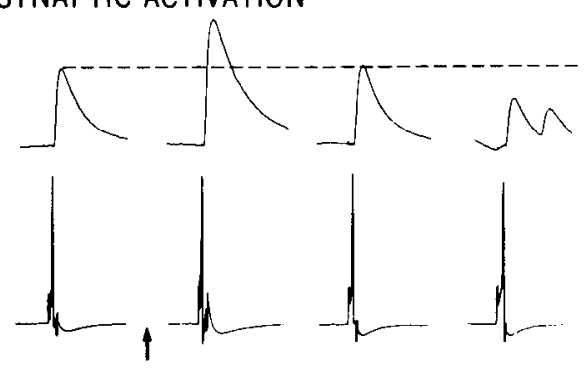

B. TEST STIMULI ALONE

MN

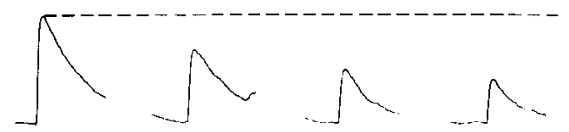

SN 2

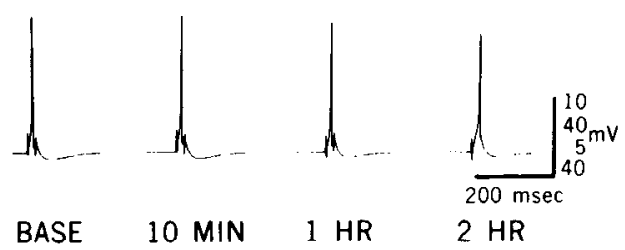

Figure 4. Examples of monosynaptic EPSPs in cells receiving homosynaptic activation (Homo training) or testing alone. The motor neuron $(M N)$ is the same in $A$ and $B$ and it received monosynaptic EPSPs from two simultaneously recorded sensory neurons ( $S N 1$ and $S N 2$ ). $A$, Homosynaptic activation. Following the high frequency activation sequence (arrow), the EPSP from $\mathrm{SN} 1$ showed clear enhancement at $10 \mathrm{~min}$ followed by progressive reduction with continued testing. $B$, Test stimuli alone (no homo- or heterosynaptic training stimulation) caused simple depression of the EPSP from SN2.

synaptic activation is small but cannot be excluded $2 \mathrm{hr}$ after training. It is also possible that the Homo training procedure inadvertently produced some heterosynaptic effects; the bursts in individual sensory neurons in the Homo group (Fig. 3) could have activated heterosynaptic facilitatory interneurons (see Hawkins et al., 1981) that affected the test synapse. Indeed, the "hump" in the test-alone group's response curve on the 10- and 20-min tests suggests that some heterosynaptic facilitation may have been produced in this control group by activation of single cells during the Homo training sequence. Any general facilitation, however, was weak since 6 of 11 test-alone cells showed'a smaller response $10 \mathrm{~min}$ after training of the Homo cell than they did on the last base line trial (e.g., Fig. $4 B$ ). Nevertheless, the enhancement in the Homo group may reflect a small heterosynaptic component as well as the homosynaptic component.

Effects of pairing homosynaptic activation with heterosynaptic stimulation. Since the explicit pairing of homosynaptic activity with

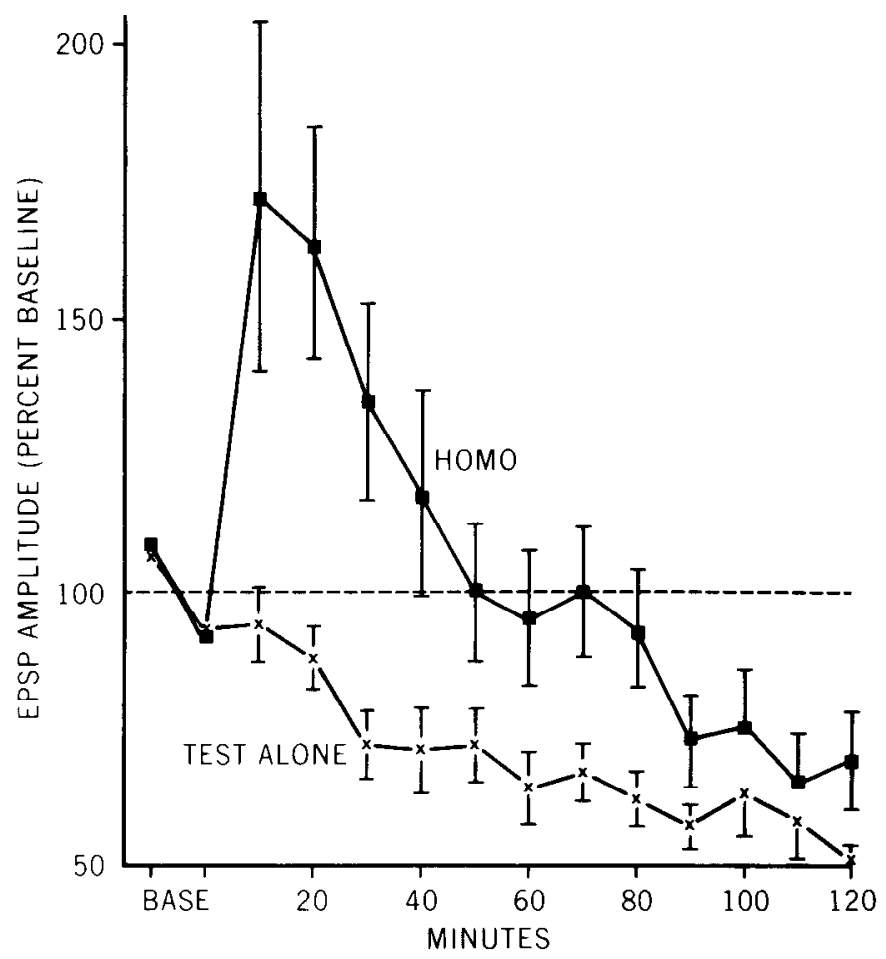

Figure 5. Mean ( \pm SEM) EPSP amplitudes of cells receiving homosynaptic activation (Homo; $N=11$ ) or testing alone ( $N=12$ ). High frequency activation of each cell in the Homo group occurred about $30 \mathrm{sec}$ after the second base line test.

heterosynaptic modulation from skin stimulation had been shown previously in the tail sensory neurons to result in associatively specific synaptic facilitation (Walters and Byrne, 1983a), we were interested in comparing the degree of long-term enhancement produced by Homo training to the effects of heterosynaptic modulation alone (Hetero training) and to the effects of paired homosynaptic activation and heterosynaptic modulation (paired-soma training). During pairedsoma training one cell received the homosynaptic activation sequence in the soma simultaneously with peripheral nerve shock (Fig. 6). The other (inactive) sensory cells recorded in the same preparation were exposed only to the effects of heterosynaptic modulation from the nerve shock (Hetero training). Presumably the Hetero tail sensory neurons did not have axons in the stimulated nerve. Prominent polysynaptic input to the motor neuron as well as hyperpolarizing responses in the inactive sensory neurons (Fig. 6) were invariably produced in preparations that showed heterosynaptic facilitation of monosynaptic EPSPs. In addition, activation of sensory neurons during the paired-soma training resulted in long-lasting depolarization of the sensory neuron (see below and SN3 in Fig. 6). 


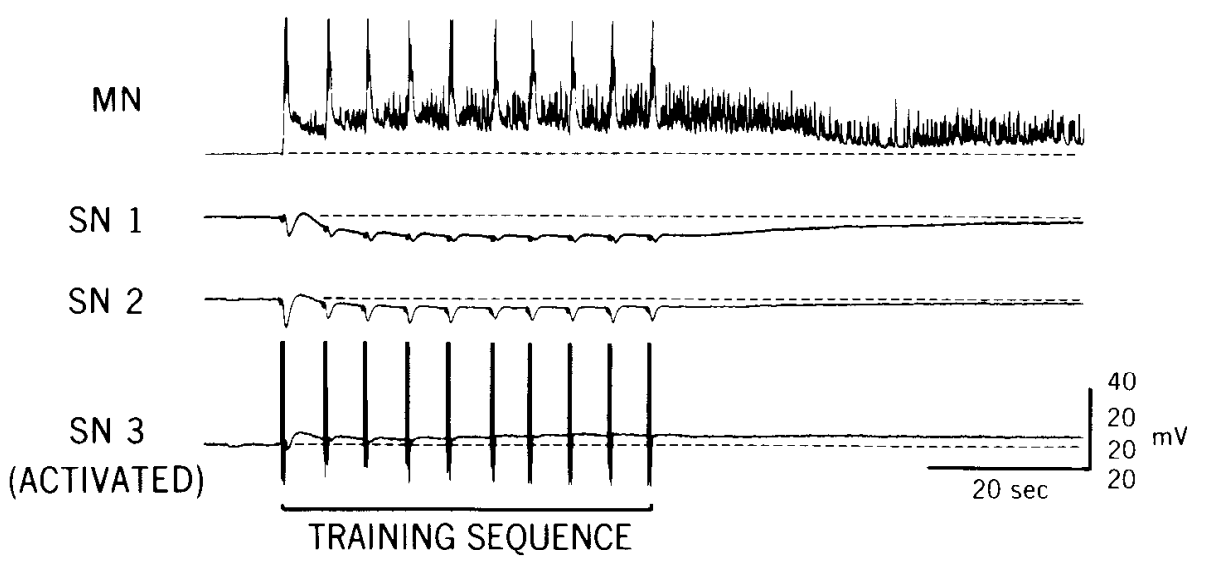

Figure 6. Training with paired homosynaptic and heterosynaptic stimulation (paired-soma) and with heterosynaptic stimulation alone (Hetero). Recordings from a tail motor neuron $(M N)$ and tail sensory neurons (SN 1 to $S N$ 3) during the combined training sequence. SN 3 received paired-soma training - a homosynaptic activation sequence applied to the soma (see Fig. 3) paired with simultaneous stimulation of a nerve. $\mathrm{SN} 1$ and SN 2 received Hetero training - the heterosynaptic effects of the nerve stimulation. The nerve stimulation caused prolonged excitatory input to the motor neuron and hyperpolatizing responses in the inactive sensory neurons (SN 1 and $\mathrm{SN}$ 2). None of these sensory neurons had axons in the stimulated nerve. Note the prolonged depolarization of the sensory neuron (SN 3) that was activated by the intracellular depolarizing pulses. Action potentials are clipped by the pen recorder.

\section{A. PAIRED STIMULATION}

$M N$

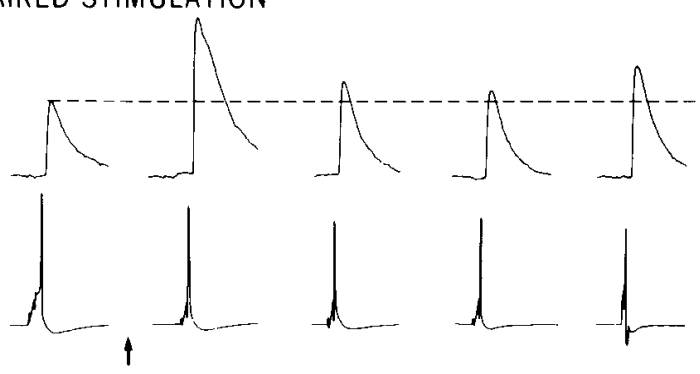

B. HETEROSYNAPTIC STIMULATION

MN

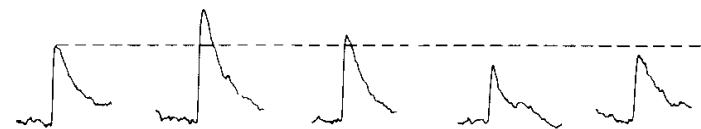

SN 2

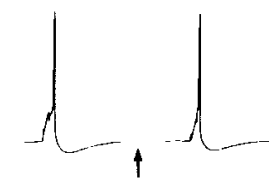

BASE

10 MIN

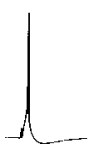

$1 \mathrm{HR}$

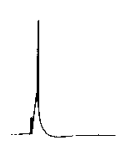

$2 \mathrm{HR}$

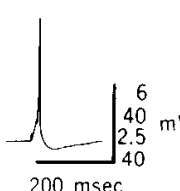

$4 \mathrm{HR}$
Figure 7. Examples of monosynaptic EPSPs in cells receiving paired-soma training and Hetero training. The two sensory neurons (SN1 and $S N 2$ ) were recorded simultaneously. The motor neuron $(M N)$ is the same in $A$ and $B$. The training sequence occurred at the arrows. Tests were delivered at 10 min intervals for $2 \mathrm{hr}$ after training and then were delivered at 1 - $\mathrm{hr}$ intervals. $A$, Paircd stimulation. The monosynaptic EPSP remained enhanced relative to the base line for as long as the cells were examined ( $4 \mathrm{hr})$. $B$, Heterosynaptic stimulation. The enhancement of the EPSP was smaller and showed less persistence than the enhancement produced by paired training in the same preparation $(A)$.

The persistent enhancement of the monosynaptic EPSP by pairedsoma training is illustrated in Figure 7A. By contrast, a cell in the same preparation exposed only to the modulatory effects of the nerve shock showed transient heterosynaptic facilitation relative to its base line (Fig. 7B). Pooled results from the paired-soma and Hetero groups are shown in Figure 8. Two hours after training, the paired-soma group's responses were enhanced significantly compared to the Hetero group's on the same trial $\left(t_{15}=5.5, p<0.005\right)$. Although the Hetero group did not show long-term enhancement relative to its own base line, it might still be enhanced relative to the test-alone group since long-lasting heterosynaptic facilitation has been observed in these cells (Walters et al., 1983b). Indeed, when compared on the 90- and 120-min tests to the test-Alone group, the Hetero group showed significant enhancement $\left(t_{32}=1.93\right.$ and 2.71 ,

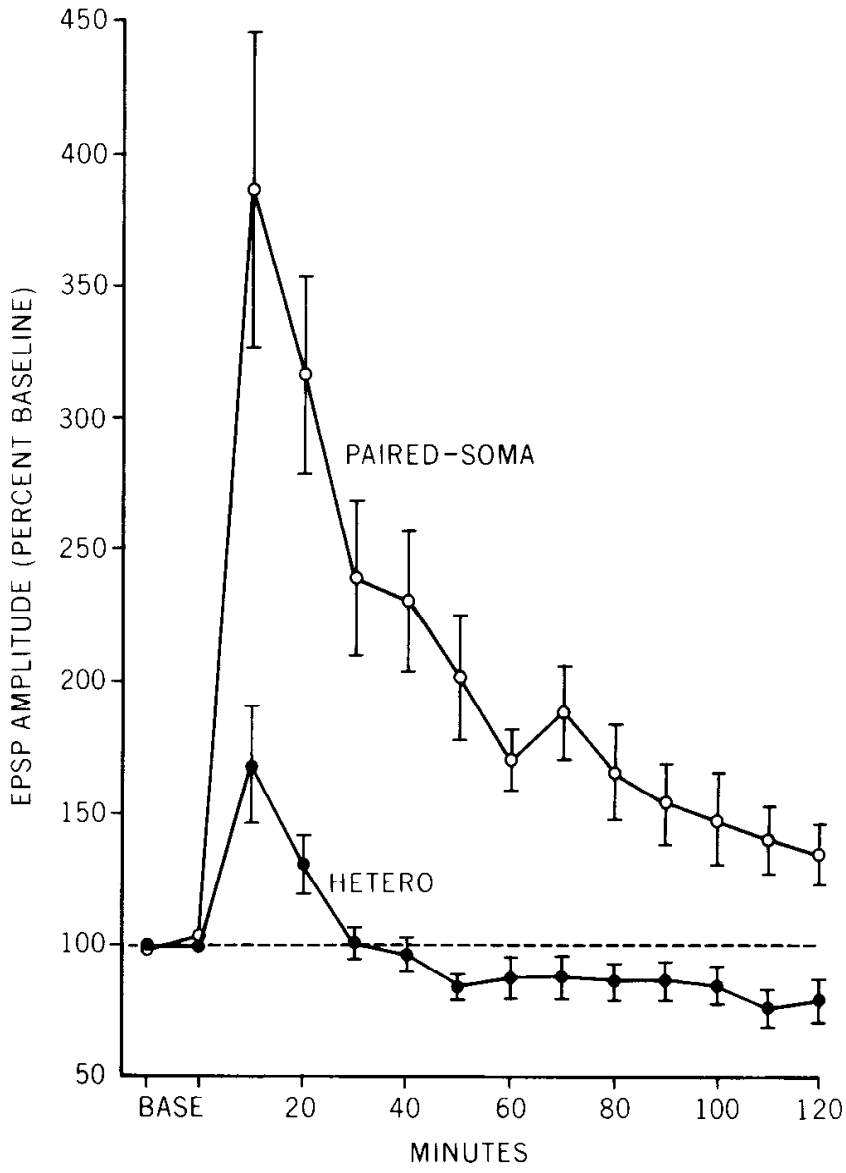

Figure 8. Mean ( \pm SEM) EPSP amplitudes for cells receiving paired-soma training (soma activation paired with nerve shock, $N=16$ ) or Hetero training (nerve shock without activation of the sensory neuron; $N=23$ ). Training stimuli were delivered after two base line tests.

respectively; $p<0.05$ and 0.01 , one-tailed $t$ test for independent groups). However, as with the Homo group, the differences were not significant on the 100- and 110-min tests, and, thus, this longerterm enhancement must be considered weak.

If long-term enhancement can be produced by pairing high frequency activity in a single neuron with heterosynaptic facilitatory input, one would predict that the subset of sensory neurons whose axons are directly activated by the nerve shock in these experiments (Fig. 1B) should also show persistent enhancement. Indeed, such an enhancement from paired axon activation might underlie the "LTP" of the complex EPSP from nerve shock described above. 

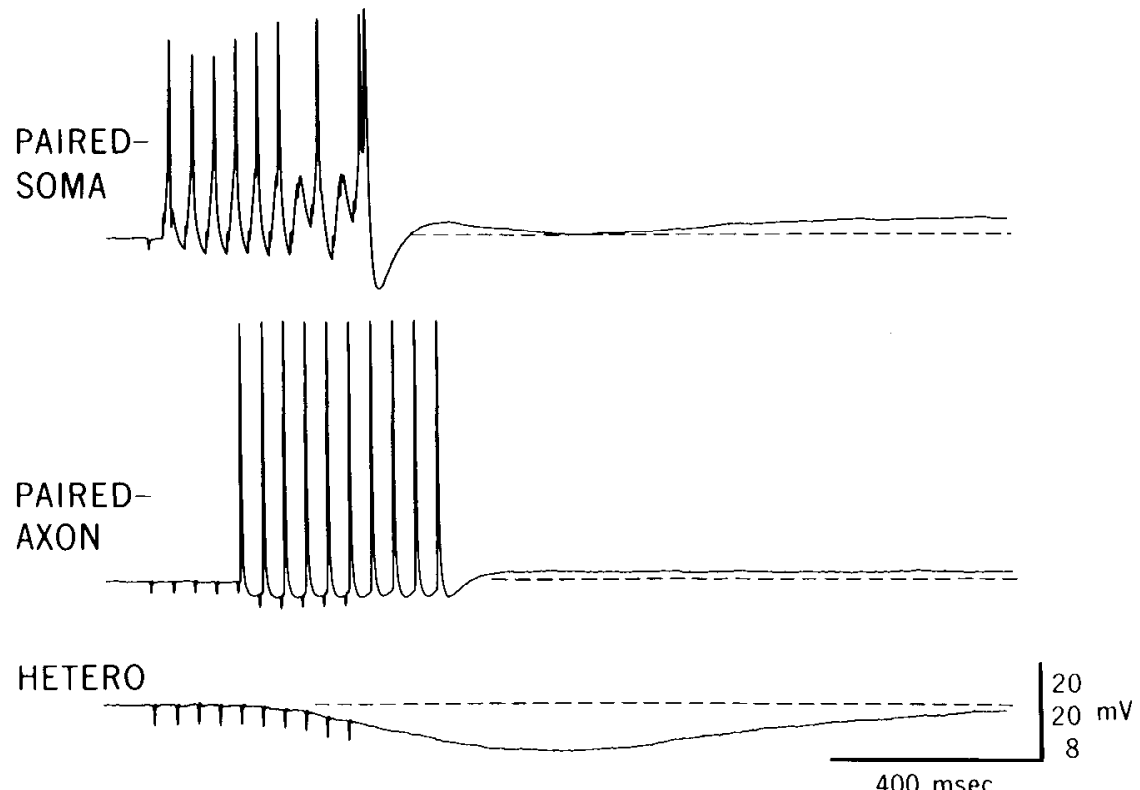

Figure 9. Responses of sensory neurons during two types of paired training. Simultaneous recordings from three sensory neurons during the first high frequency train of the LTP training sequence are illustrated. One cell (paired-soma) was activated by intracellular stimulation al the same time that nerve shocks were applied (downward artifacts in each record). This cell did not have its axon in the stimulated nerve (see below). A second cell (paired-axon) had its axon activated by the nerve shocks themselves. The lag in the burst in this cell reflects the conduction delay from the site of shock to the nerve. The third cell (Hetero) shows the hyperpolarizing response typical of inactive sensory neurons during intense heterosynaptic stimulation. Note the persistent depolarization in both of the activated (paired) sensory neurons.
Figure 9 illustrates the simultaneously recorded responses of a somaactivated (paired-soma), an axon-activated (paired-axon), and an inactive sensory neuron (Hetero) during a train of nerve shock. Axon stimulation (via the suction electrode on the nerve) produced onefor-one action potentials with about the same frequency as those elicited at the same time in the other sensory neuron by soma stimulation. Because of conduction time from the nerve, there was about a $140-\mathrm{mscc}$ delay for the action potentials to reach the soma of the axon-activated cell. Both paired cells showed a persistent depolarization following activation, in contrast to the hyperpolarization in the Hetero cell. Like the paired-soma procedure, the pairedaxon procedure produced significant synaptic enhancement compared to the Hetero procedure when measured $2 \mathrm{hr}$ after training $\left(t_{10}=3.7, p<0.005\right)$.

Comparison of enhancement procedures. Each of the cellular training procedures described above produced characteristic changes in the monosynaptic EPSP from the sensory neurons. As shown in Figure 10, the two paired training procedures appeared to produce enhanced synaptic test responses compared to the Homo, Hetero, and test-alone procedures. An analysis of variance on the 2-hr test revealed an overall significant effect of type of training $\left(F_{3}\right.$ $=13.8, p<0.001$ ). Subsequent pairwise comparisons with the Newman-Keuls procedure showed that both paired groups were significantly potentiated compared to the Homo, Hetero, and testalone groups at the 0.01 level. Differences among the paired-soma, paired-axon, and Homo groups are unlikely to be due to differences in the number of action potentials evoked in each group during training since the average numbers of spikes elicited in the activation sequence were about the same; $81 \pm 18,81 \pm 18$, and $87 \pm 9$ spikes, respectively (mean $+\mathrm{SD}$ ).

Testing alone produced significant synaptic depression as judged by comparing the second base line test to the 120 -min test in the test-alone group $\left(t_{10}=12.9, p<0.001\right)$. Although comparisons of the Homo and Hetero groups to the test-alone group indicated some enhancement from each of these procedures lasting for $120 \mathrm{~min}$ (see preceding sections), the enhancement in the Homo and Hetero groups was not sufficient to offset the depression produced by repeated testing. Indeed, comparison of the second base line test to the 120-min test revealed a significant depression in the Homo and Hetero groups $\left(t_{10}=2.51\right.$ and $t_{22}=3.83$, respectively; $p<$ 0.025 and 0.005 , respectively). By contrast, a comparison of the second base line test to the 120-min test in the paired-soma and paired-axon groups revealed a significant enhancement $\left(t_{15}=2.52\right.$ and $t_{8}=2.28$, respectively; $p<0.025$ and 0.05 , respectively.).

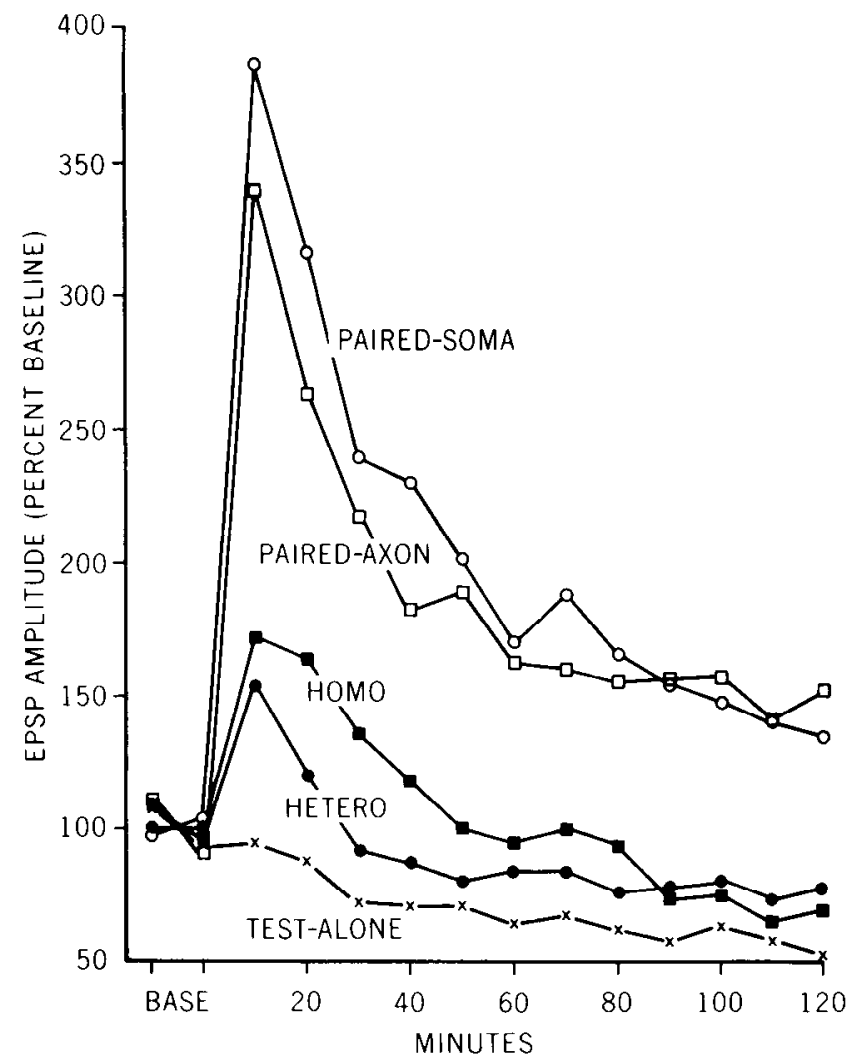

Figure 10. Comparison of monosynaptic EPSPs following each of the five training procedures applied to individual sensory neurons. See "Materials and Methods" for a description of each training proccdurc.

Duration of monosynaptic enhancement. Although the enhanced EPSP amplitude in the paired groups showed a progressive decline after training, this decline slowed after about an hour to parallel approximatcly the changes in EPSP amplitude observed in the testalone group. This suggested the possibility of an underlying stable enhancement, with the late decline observed in the EPSP due largely to superimposed depression from the continued testing. To see whether monosynaptic enhancement persisted beyond $2 \mathrm{hr}$, we increased the test interval after the 2-hr test from $10 \mathrm{~min}$ to $1 \mathrm{hr}$ and continued to test at 1-hr intervals for as long as we could hold the 


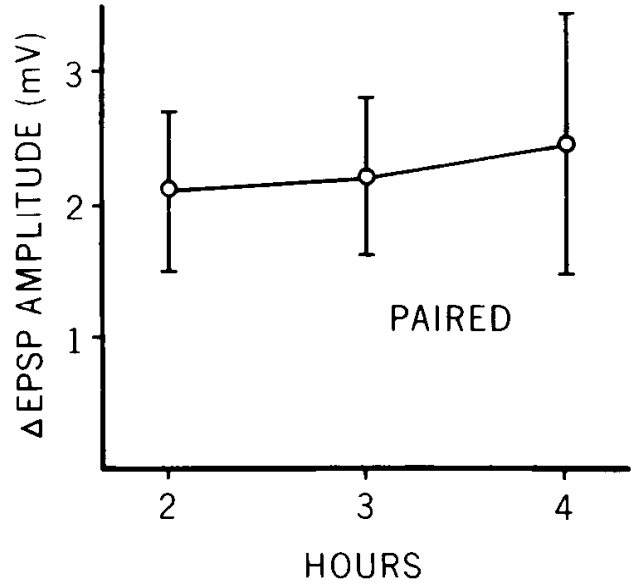

Figure 11. Enhancement persists for at least $4 \mathrm{hr}$. The change (relative to the base line) of the EPSPs measured 2, 3, and $4 \mathrm{hr}$ after paired training ( $N$ $=9$, paired-soma and paired-axon combined) is shown. The bars indicate SEM. Prior to these tests (delivered at 1 -hr intervals), the cells had been tested at $10 \mathrm{~min}$ intervals. Consequently, the slope of this curve may also be influenced by recovery from synaptic depression produced by the earlier testing.

cells. We were able to examine nine cells 3 and $4 \mathrm{hr}$ after paired training (Fig. 11). On the 4-hr test these cells still showed significant enhancement compared to their average base line response $\left(t_{8}=\right.$ $2.3, p<0.05$ ). Because of the increased test interval after $2 \mathrm{hr}$, we do not know whether the absence of a further decrease in response on the 3-and 4-hr tests is due to recovery from depression or to a lack of decay of enhancement.

Too few cells in the other groups were held beyond $2 \mathrm{hr}$ to allow statistical comparisons among the groups at the longer test intervals. However, a rough indication of the duration of each form of plasticity was obtained by calculating time constants for the decay of enhancement in each group using nonlinear regression methods. In order to estimate what the effects of training would be in the absence of superimposed depression caused by the repeated testing, we assumed that the test-alone group provided a simple estimate for the degree of synaptic depression expected during the testing of each group. We thus subtracted the test-alone curve from each of the other curves in Figure 10 as a crude correction for synaptic depression. The decay of enhancement in the Homo group was fit closely with a single exponential having a time constant of $55 \mathrm{~min}$. The decay curves for the paired and Hetero groups were fit best by an equation containing the sum of two exponential terms. The time constants for the first component of the curves of the paired and Hetero groups were 18 and $19 \mathrm{~min}$, respectively. The time constants of the second component, however, were considerably longer (and longer than the single time constant of enhancement in the Homo group): over $5 \mathrm{hr}$ in the paired group and virtually "infinite" for the Hetero group (i.e., the decay curves for the Hetero and test-alone groups showed no convergence between the 30-min test and the 120-min test-see Fig. 10).

Enhancement of excitability of the soma. In view of previous reports of plastic changes in electrophysiological and biochemical features measured in the soma of Aplysia sensory neurons (see "Discussion"), we wanted to see whether enhancement of the tail sensory neuron synapses was associated with long-term changes in the soma as well. In 14 cells from the paired groups and 12 from the Hetero group we measured the threshold for action potential generation in the soma on each test by measuring the minimum current necessary to elicit an action potential (see "Materials and Methods"). Since observed threshold should be highly sensitive to the health of the cell soma, we excluded from analysis sensory neurons that were not held for at least one additional hour after the 2-hr test. In addition, we excluded cells that showed unusually large (exceeding $2 \mathrm{nA}$ ) increases in threshold. Such increases occurred

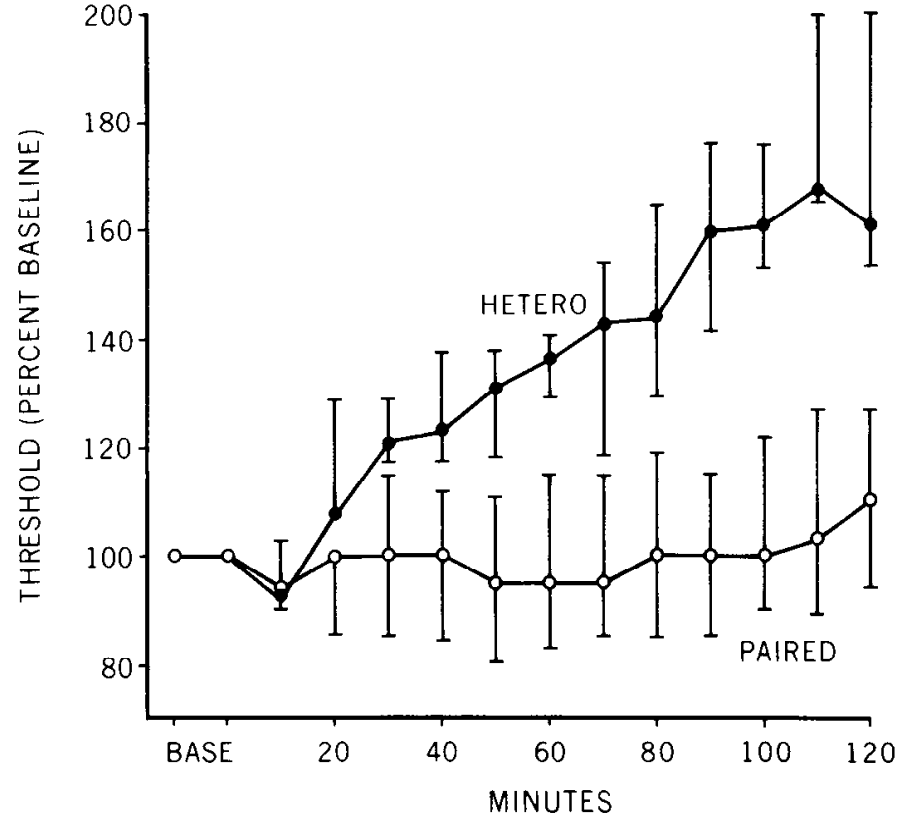

Figure 12. Long-term relative enhancement of excitability of the sensory neuron soma. The median thresholds for action potential generation are plotted, normalized to the average base line current and shown with interquartile range. Threshold was defined as the minimum current required to elicit an action potential by injecting depolarizing current into the soma Paired training ( $N=8$, paired-soma and paired-axon combined) resulted in a depression of action potential threshold relative to the progressively increasing thresholds seen in the Hetero group $(N=6)$.

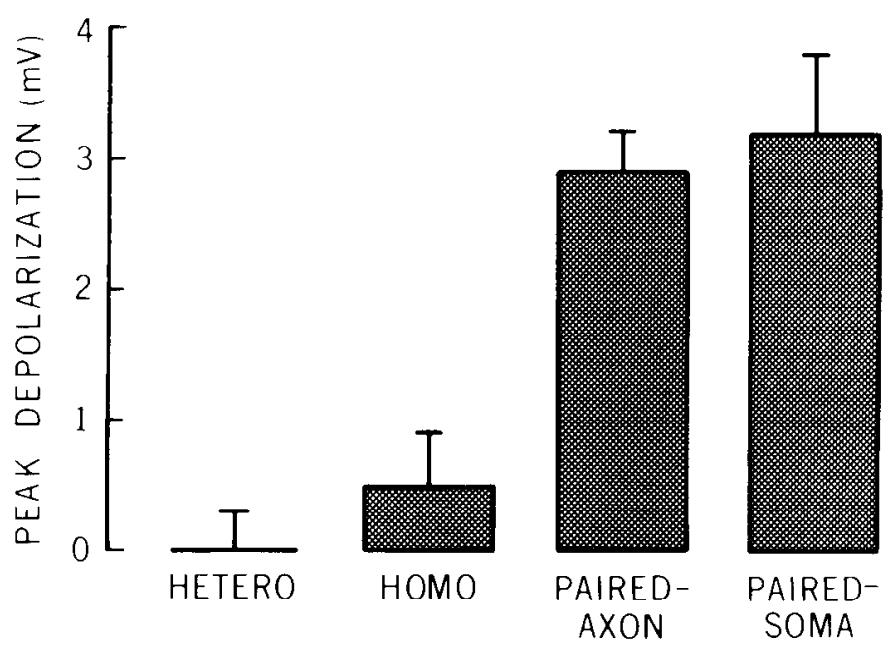

Figure 13. Short-term correlates of enhancement in the sensory neuron soma. The mean "peak depolarization" ( \pm SEM) are plotted. The peak depolarization is defined as the most depolarized (or least hyperpolarized) level of membrane potential in the interval beginning $5 \mathrm{sec}$ after the last training stimulus and ending 2 min after the last training stimulus (see Figs. 3 and 6 , and Walters and Byrne, 1983b). Both forms of paired training ( $N=31$ for soma and 13 for axon) produced large peak depolarizations relative to Hetero $(N=33)$ and Homo $(N=16)$ training.

late in testing in one cell from each group and presumably reflected a shift in electrode position within the cell. Examples of the action potentials triggered at threshold are illustrated in Figure 7. The changes in threshold for cells in the paired $(N=8)$ and Hetero $(N$ $=6$ ) groups are shown in Figure 12. The Hetero cells displayed a steady increase in threshold following a brief decrease 10 min after training. Such progressive increases in threshold were also seen in all of the Homo and test-alone cells examined, but too few cells ( $N$ $=2$ and 3, respectively) were examined to allow statistical compar- 
isons. We do not know yet whether these progressive changes are related to continued testing or reflect changes due to impalement or maintenance of the in vitro preparation. By contrast, the paired groups showed much less of an increase in threshold and thus showed a relative increase in excitability compared to the Hetero celis. Two hours after training the paired thresholds were significantly lower than the Hetero thresholds $\left(U_{6,8}=4, p=0.008\right.$; Mann-Whitney $U$ test, two-tailed).

In addition to this long-term enhancement of excitability produced by pairing, we also found a reliable short-term effect of pairing-a slow depolarizing response in the soma following activation (see Fig. 6; cf. Fig. 3). These depolarizing responses appeared to last several minutes and resembled the slow responses seen during associative conditioning of the tail sensory neurons using cutaneous stimulation (Walters and Byrne, 1983b). We compared these responses quantitatively by measuring the "peak depolarization" (see Walters and Byrne, 1983b) in the period beginning $5 \mathrm{sec}$ after and ending 2 min after the last training stimulus (Fig. 13). This measure, since it is of the most depolarized level in the interval, does not indicate the degree of hyperpolarization in the interval. Hyperpolarization almost never occurred after paired or Homo training but was observed in every Hetero cell (Figs. 3, 6, and 9). An analysis of variance revealed an overall significant effect of type of training $\left(F_{3}\right.$ $=20.3, p<0.001$ ). Pairwise comparisons using the Newman-Keuls procedure then showed that both paired groups were significantly more depolarized than the Hetero and Homo groups at the 0.01 level. Because of uncertainties in long-term measurement of membrane potential, we do not know how long small differences in membrane potential among these groups persisted beyond this initial period. We also do not know the extent to which changes in membrane potential contributed to the relative enhancement of soma excitability.

\section{Discussion}

These experiments provide the first examination of long-term synaptic enhancement in which both the pre- and postsynaptic neurons were recorded and controlled with intracellular electrodes. This simple experimental preparation provides novel perspectives on cellular mechanisms underlying long-term plasticity and may begin to suggest at least one biological function of LTP-like phenomena.

Mechanism of long-term enhancement. The pairing of high frequency action potential activity with heterosynaptic modulation produced enhancement of the monosynaptic EPSP from tail sensory neurons that persisted for at least $4 \mathrm{hr}$ and which may last considerably longer. Since the enhancement of the monosynaptic EPSP produced by either homosynaptic activity or heterosynaptic modulation alone was considerably weaker than the effects of explicitly pairing the two, we conclude that an interaction of high frequency homosynaptic activity and heterosynaptic modulation can underlie the development of powerful, long-term synaptic memory. This synaptic memory from activity-dependent modulation is not simply a summation of the effects of activity alone and heterosynaptic modulation alone since the sum of the mean Homo and Hetero differences from test-alone responses is less than the difference between the paired groups and the test-alone responses (Fig. 10). Because the nerves we used to examine enhancement of the complex EPSP (LTP) contained axons of tail sensory neurons making monosynaptic connections to the same postsynaptic cells that were used to measure the complex nerve-evoked EPSPS, we think it probable the long-term enhancement of these monosynaptic connections underlies, at least in part, the "LTP" of the complex EPSP produced by nerve stimulation. The smaller early enhancement of the complex EPSP compared to the monosynaptic EPSP could reflect a lack of comparable plasticity in some of the interneuronal synapses involved in the complex EPSP. It might, however, merely reflect a smaller capacity for the larger complex EPSP to facilitate because of nonlinear summation and closer proximity to the synaptic reversal potential.

In this preparation the alterations may largely be presynaptic Since a single motor neuron was used to measure (concurrently) the responses of the cells given paired training and the cells given Hetero training, differences between these groups cannot be attributed to generalized changes in the post-synaptic cell. Additional support for a presynaptic change comes from the fact that training produced a long-term alteration of at least one measurable property of the presynaptic cell, producing a relative enhancement of the excitability of the sensory neuron soma. Furthermore, activity paired with heterosynaptic modulation in other sensory neurons in Aplysia has produced changes in action potential duration that have been linked to presynaptic facilitation (Hawkins et al., 1983). However, until a quantal analysis is performed on the enhanced synapses, we cannot conclusively decide whether long-term enhancement involves changes in transmitter release or in specific postsynaptic properties.

Nerve shock alone causes short-term heterosynaptic facilitation of inactive sensory neurons in Aplysia that is produced, at least in part, by a reduction in a serotonin-sensitive resting $\mathrm{K}^{+}$conductance (Klein and Kandel, 1980; Byrne and Walters, 1982; Pollock et al., 1982; Walsh and Byrne, 1984). The reduction in the outward current prolongs the action potential, allowing more $\mathrm{Ca}^{2+}$ influx and thus greater transmitter release (Klein et al., 1980). The smaller resting $\mathrm{K}^{+}$conductance would also be expected to decrease the threshold for action potential generation. Thus, this mechanism might be involved in both the long-term synaptic enhancement and the enhancement of soma excitability observed in the tail sensory neurons after paired training.

A basis for the interaction of homosynaptic activity with heterosynaptic modulation is provided by the activity-dependent neuromodulation model proposed independently by Walters and Byrne (1983a) and Hawkins et al. (1983). In particular, since heterosynaptic facilitation is mediated intracellularly by cAMP (see Kandel and Schwartz, 1982, for review; see also Pollock et al., 1982; Ocorr et al., 1983, 1985), and since action potential activity appears to result in $\mathrm{Ca}^{2+}$ influx (Walters and Byrne, 1983b), we suggested that $\mathrm{Ca}^{2+}$ influx during action potential activity primes the adenylate cyclase, amplifying cAMP synthesis in response to the heterosynaptic input. Ocorr et al. (1983, 1985) and Abrams et al. (1983) have recently obtained evidence supporting this possibility in Aplysia, and strikingly convergent observations related to associative learning have also been made in Drosophila (Livingstone et al., 1984). Such an associative amplification of CAMP levels should cause a further reduction in the $\mathrm{K}^{+}$conductance and thus might underlie the increase in synaptic strength and the relative reduction in action potential threshold observed after paired training. The relatively long-lasting depolarization following paired training might also contribute to enhanced cyclase activity by allowing further influx of $\mathrm{Ca}^{2+}$ through voltage-dependent channels (Walters and Byrne, 1983b) during a period in which some neuromodulatory input may continue. Conversely, the hyperpolarization of the inactive cells by the heterosynaptic stimulation might reduce tonic $\mathrm{Ca}^{2+}$ influx, possibly reducing cyclase activity (Walters and Byrne, 1983b).

This model, being based on analyses of short-term plasticity in Aplysia neurons, does not explain the long-term retention of changes in transmitter release or action potential threshold. However, in other sensory neurons in Aplysia, Hawkins et al. (1983) found relatively long-term changes in spike duration produced by activity-dependent neuromodulation that might be explained by a persistence of the effects in this model. Moreover, our recent finding that the pairing of depolarization with a presumptive heterosynaptic modulator (serotonin) enhances CAMP levels in the sensory neuron soma (Ocorr et al., 1983, 1985) supports the speculative possibility that CAMP might affect long-term cellular regulatory systems localized to the soma. For example, the enhanced CAMP levels might influence protein 
synthesis or genetic regulation (e.g., Klein and Berg, 1980; Costa et al., 1976; see also Kandel \& Schwartz, 1982).

Homosynaptic activation alone ${ }^{3}$ produced enhancement that appeared to decay slowly compared to PTP described in these synapses (see Walters and Byrne, 1984). However, the decay of longterm enhancement produced by heterosynaptic modulation alone and by paired homo- and heterosynaptic modulation was even slower. The similarities in the kinetics of paired and Hetero enhancement suggest (1) that heterosynaptic modulation alone can underlie long-lasting memory (which would be consistent with a role in longterm nonassociative modifications such as the sensitization reported by Pinsker et al. (1973) and Walters (1980)), and (2) that the amplitude of long-term enhancement can be amplified by pairing activity in the cell with the heterosynaptic cnhancement signal. The long-term amplification of heterosynaptic facilitation by paired activity described here may be an extension of the amplification produced by differential cellular conditioning procedures using cutaneous stimulation (Walters and Byrne, 1983a) and is consistent with the possibility that long-term associative memory can result from activitydependent amplification of cAMP synthesis.

Our observation of persistent synaptic enhancement in the Homo group appears to be consistent with models of LTP in the mammalian hippocampus based upon homosynaptic activity alone (Fig. 14A; e.g., McNaughton, 1983; Lynch and Baudry, 1984). Since the apparent time constant of Homo enhancement in our system is similar to that reported in the superior cervical ganglion (Brown and McAfee, 1982) and to the shorter component of LTP in the hippocampus (e.g., "LTP 1;" Racine et al., 1983), it will be interesting to examine whether these various forms of intermediate-duration synaptic plasticity share common determinants.

In addition, our observation of long-term enhancement produced by heterosynaptic modulation alone appears to have parallels in other systems (Yamamoto and Chujo, 1978; Johnston et al., 1983; Neuman and Harley, 1983). Since both heterosynaptic modulation alone and paired training in our system produce synaptic enhancement that decayed with much longer time constants than those for the Homo enhancement, it will also be interesting to look for parallels (such as the necessity of a heterosynaptic chemical signal) between these longer-lasting forms of enhancement in Aplysia and the longer components of LTP in the mammalian brain (e.g., "LTP 2;" Racine et al., 1983).

It is interesting that activity-dependent neuromodulation fits two general observations of long-term enhancement in other preparations. First, it can explain the induction or augmentation of synaptic enhancement by application of neuromodulators such as norepinephrine in the hippocampal slice (Hopkins and Johnston, 1984) and octopamine at the crayfish neuromuscular junction (Breen and Atwood, 1983). Second, it provides a novel view of the processes underlying "associative LTP" in the hippocampus. LTP is highly dependent upon the intensity of the stimulus train (Bliss and GardnerMedwin, 1973; Schwartzkroin and Wester, 1975; McNaughton et al., 1978). Moreover, concurrent activation of two separate pathways can produce LTP at intensities below that needed to produce LTP by stimulating either pathway alone (McNaughton et al., 1978; Robinson and Racine, 1982; Lee, 1983). Finally, associating weak stimulation of one pathway with strong stimulation of another can produce LTP in the weak pathway when stimulation of either pathway alone does not (Barrionuevo and Brown, 1983; Levy and Steward, 1979,1983 ). Each of these observations has parallels in Aplysia (see above, and unpublished observations) and can be explained

\footnotetext{
${ }^{3}$ However, since tail sensory neuron activity appears capable of recruiting heterosynaptic facilitation under some conditions (Fig. 5 and unpublished observations; see also Walters et al., 1983b), it is possible that the small degree of long-term enhancement observed in the Homo group reflects an interaction with a small amount of heterosynaptic modulation recruited by the activated sensory neuron.
}

\section{LTP MODELS}
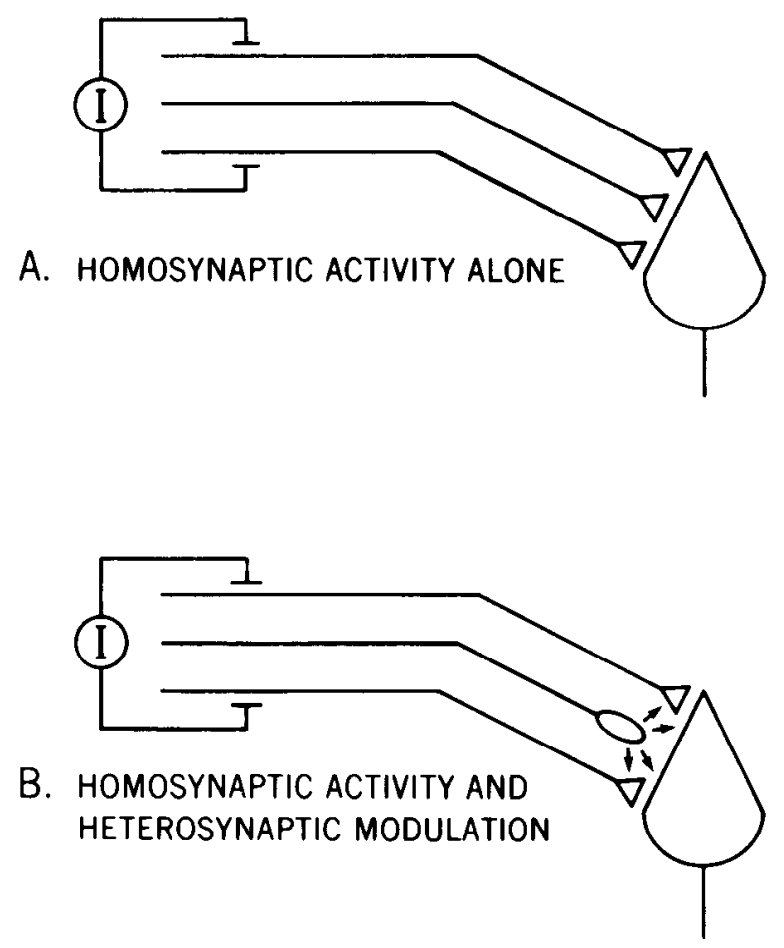

Figure 14. Models of LTP produced by high frequency extracellular stimulation of a neural pathway. I indicates the stimulus current. In both models the plastic changes can be pre-, post-, or both pre- and postsynaptic. $A$, Homosynaptic activity alone. Activation of the axons of the test synapses results in intrinsic changes within each active synapse, leading to LTP. $B$, Homosynaptic activity and heterosynaptic modulation. Stimulation of the heterogeneous pathway activates both the test synapses and parallel (or, alternatively, recurrent) modulatory fibers. Such paired activity in the test synapses amplifies the long-term effects of the released neuromodulatory substances on the test synapses. The same interaction of spike activity and extrinsic chemical signals might also occur in the trigger zone and cell soma, increasing excitability and influencing long-term cellular regulatory systems in the nucleus (see "Discussion").

by assuming that the neuromodulatory input necessary for activitydependent modulation has a discrete threshold (see also Hopkins and Johnston, 1984). By this view the high frequency train must be intense enough to activate neuromodulatory fibers as well as the test synapses (Fig. 14B). In addition, enough neuromodulatory fibers must be activated concurrently by the electrical stimulus to cause a sufficient increase in concentration of the modulator(s) around the activated test cells. (Our activity-dependent modulation model of LTP (Fig. 14B) does not distinguish between pre- and postsynaptic sites for LTP. In fact, if effects like those we observed in the tail sensory neurons were to occur in an interneuron (e.g., in the hippocampus), presynaptic effects (enhanced transmitter release) and postsynaptic effects (enhanced excitability) might occur within the same cell. Thus, activity-dependent modulation might cause long-term effects pre-, post-, or both pre- and postsynaptically at various stages of a tetanized pathway. It is interesting that recent interpretations of LTP in the hippocampus also suggest both preand postsynaptic alterations (Bliss and Dolphin, 1982). It is also possible that activity-dependent modulation could be completely supported by homosynaptic activity alone if the synapse co-releases both an excitatory transmitter and a neuromodulator that recurrently modulates the releasing synapse.)

An attractive feature of this model as a mechanism for information storage is that it does not require the massive coactivation of afferent fibers typically used in studies of LTP. Some investigators have been 
concerned that such artificial coactivation patterns may not be physiologically meaningful (Swanson et al., 1982). Our results suggest that LTP can be produced by pairing appropriate neuromodulatory input with naturally occurring activity patterns in one or a few cells (Fig. 14B) and, thus, that the requirements for LTP might easily be met during normal behavior. Simple, general mechanisms underlying LTP would also be consistent with the occurrence of LTP-like phenomena in "lower" preparations such as Aplysia, crayfish, and the superior cervical ganglion.

Although we believe that this model suggests potential mechanisms of LTP which should be considered in studies of the mammalian brain, we do not claim that LTP in the hippocampus is identical to long-term enhancement in the tail withdrawal reflex of Aplysia. First, we do not yet know whether enhancement in Aplysia can last for weeks or longer as LTP can in the hippocampus (Bliss and Gardner-Medwin, 1973; Barnes, 1979). Second, short-term heterosynaptic facilitation appears to be weak or absent in much of the mammalian forebrain (Baranyi and Feher, 1978; Robinson and Racine, 1982). Third, axoaxonic synapses, thought to be involved in presynaptic facilitation in Aplysia (Bailey et al., 1981), have not been demonstrated in the hippocampus. Fourth, changes in threshold for action potential generation in response to intracellular current injection have not been demonstrated during hippocampal LTP. Nevertheless, these potential differences do not affect the major predic tions of our model (Fig. 14B). In particular, the extrinsic neuromodulator that triggers LTP (which would be amplified by paired activity in the cell or synapse) could be hormonal and need not itself produce measurable short-term facilitation, particularly if the short-term effects are masked by concurrent heterosynaptic depression. The important point is that paired electrical activity may amplify an extrinsic chemical signal that triggers intrinsic biochemical changes leading to longterm cellular memory (Fig. 14B).

Function of long-term enhancement. A useful feature of this preparation is that the function of the cells showing the enhancement is relatively well known and, thus, this system may provide general suggestions about the function of long-term changes in signaling effectiveness. The tail sensory neurons relay information to the rest of the nervous system about mechanosensory or injurious events occurring at the animal's tail (Walters et al., 1983a). Information from the tail can have various behavioral consequences, including the elicitation of several defensive reflexes and locomotion (Walters et al., 1981, 1983a), the modulation of fceding bchavior (Kupfermann and Weiss, 1981), and even the classical conditioning of reflex responses (Carew et al., 1981, 1983). If the general signaling effectiveness of a tail sensory neuron is increased by long-term enhancement, input to the rest of the nervous system from the part of the tail represented by that cell is increased. In effect, the sensory representation of that part of the tail within the brain is strengthened, and information from that sensory channel becomes more "important" to the brain.

On the basis of the present results and others (Hawkins et al., 1983; Walters and Byrne, 1983a), we believe that "importance" can be conferred to a sensory neuron by the association of activity in that neuron with threatening or injurious stimulation of the animal. Sensory neuron activity that is closely associated in time with the release of neuromodulators by the noxious event amplifies the longterm enhancement triggered by the neuromodulator. Thus, in this system, long-term enhancement can function as a form of associative information storage, encoding a memory of the association between a sensory event and a motivational event. It seems likely that such associative memories would find expression in the examples of classical conditioning (lasting several days) involving mechanosensory pathways that have been described in Aplysia (Carew et al., 1981, 1983). In particular, we can now test the prediction that long-term enhancement of sensory neuron signaling effectiveness will underlie the classical conditioning of tail withdrawal to weak cutaneous stimulation of a site on the tail that activates these sensory neurons (Ingram and Walters, 1984).

\section{References}

Abrams, T. W., T. J. Carew, R. D. Hawkins, and E. R. Kandel (1983) Aspects of the celluiar mechanism of temporal specificity: Preliminary evidence for $\mathrm{Ca}^{2+}$ influx as a signal of activity. Soc. Neurosci. Abstr. 9: 168.

Bailey, C. H., R. D. Hawkins, M. C. Chen, and E. R. Kandel (1981) Interneurons involved in mediation and modulation of gill-withdrawal reflex in Aplysia. IV. Morphological basis of presynaptic facilitation. J. Neurophysiol. 45: 340-360.

Baranyi, A., and O. Feher (1978) Conditioned changes of synaptic transmission in the motor cortex of the cat. Exp. Brain Res. 33: 283-298.

Barnes, C. A. (1979) Memory deficits associated with senescence: A behavioral and neurophysiological study in the rat. J. Comp. Physiol. Psychol. 93: 74-104.

Barrionuevo, G., and T. H. Brown (1983) Associative long-term potentiation in hippocampal slices. Proc. Natl. Acad. Sci. U. S. A. 80: 7347-7351.

Baxter, D., and T. H. Brown (1983) Quantal analysis of long-term synaptic potentiation. Soc. Neurosci. Abstr. 9: 103.

Berger, T. W. (1984) Long-term potentiation of hippocampal synaptic transmission affects rate of behavioral learning. Science 224: 627-630.

Bliss, T. V. P., and A. C. Dolphin (1982) What is the mechanism of long-term potentiation in the hippocampus? Trends Neurosci. 5: 289-290.

Bliss, T. V. P., and A. Gardner-Medwin (1973) Long-lasting potentiation of synaptic transmission in the dentate area of unanesthetized rabbit following stimulation of the perforant path. J. Physiol. (Lond.) 232: 357-374.

Bliss, T. V. P., and T. Lomo (1973) Long-lasting potentiation of synaptic transmission in the dentate area of the anesthetized rabbit following stimulation of the perforant path. J. Physiol. (Lond.) 232: 331-356.

Breen, C. A., and H. L. Atwood (1983) Octopamine-A neurohormone with presynaptic activity-dependent effects at crayfish neuromuscular junction. Nature 303: 716-718.

Brown, T. H., and D. A. McAfee (1982) Long-term synaptic potentiation in the superior cervical ganglion. Science 215: 1411-1413.

Byrne, J. H., and E. T. Walters (1982) Associative conditioning of single sensory neurons in Aplysia. II. Activity-dependent modulation of membrane responses. Soc. Neurosci. Abstr. 8: 386.

Carew, T. J., E. T. Walters, and E. R. Kandel (1981) Classical conditioning in a simple withdrawal reflex in Aplysia californica. J. Neurosci. 1: 14261437

Carew, T. J., R. D. Hawkins, and E. R. Kandel (1983) Differential classical conditioning of a defensive withdrawal reflex in Aplysia californica. Science 219: 397-400.

Costa, E., A. Kurosawa, and A. Guidotti (1976) Activation and nuclear translocation of protein kinase during transsynaptic induction of tyrosine 3-monooxygenase. Proc. Natl. Acad. Sci. U. S. A. 73: 1058-1062.

Douglas, R. M., and G. V. Goodard (1975) Long-term potentiation of the pertorant path-granule cell synapse in the rat hippocampus. Brain Res. 86: 205-212

Gerren, R. A., and N. M. Weinberger (1983) Long-term potentiation in the magnocellular medial geniculate nucleus of the anesthetized cat. Brain Res. 265: 138-142.

Hawkins, R. D., V. F. Castellucci, and E. R. Kandel (1981) Interneurons involved in mediation and modulation of gill-withdrawal reflex in Aplysia. I. Identification and characterization. J. Neurophysiol. 45: 304-314.

Hawkins, R. D., T. W. Abrams, T. J. Carew, and E. R. Kandel (1983) A cellular mechanism of classical conditioning in Aplysia: Activity-dependent amplification of presynaptic facilitation. Science 219: 400-405.

Hopkins, W. F., and D. Johnston (1984) Frequency-dependent noradrenergic regulation of long-term potentiation in hippocampus. Science, 226: 350-352.

Ingram, D. A., and E. T. Walters (1984) Differential classical conditioning of tail and siphon withdrawal in Aplysia. Soc. Neurosci. Abstr. 10: 270.

Jahan-Parwar, B., and S. M. Fredman (1978) Pedal locomotion in Aplysia. I. Sensory and motor fields of pedal nerves. Comp. Biochem. Physiol. 60A. 459-465.

Johnston, M. F., E. A. Kravitz, H. Meiri, and R. Rahamimoff (1983) Adrenocorticotropic hormone causes long-lasting potentiation of transmitter release from frog motor nerve terminals. Science 220: 1071-1072.

Kandel, E. R. (1979) Behavioral Biology of Aplysia, W. H. Freeman, San Francisco.

Kandel, E. R., and J. H. Schwartz (1982) Molecular biology of learning: Modulation of transmitter release. Science 218: 433-443.

Klein, D. C., and G. R. Berg (1970) Pineal gland: Stimulation of melatonin production by norepinephrine involves cyclic AMP-mediated stimulation of $\mathrm{N}$-acetyltransferase. Adv. Biochem. Pharmacol. 3: 241-263.

Klein, M., and E. R. Kandel (1980) Mechanism of calcium current modulation 
underlying presynaptic facilitation and behavioral sensitization in Aplysia. Proc. Natl. Acad. Sci. U. S. A. 77: 6912-6916.

Klein, M., E. Shapiro, and E. R. Kandel (1980) Synaptic plasticity and modulation of the $\mathrm{Ca}^{2+}$ current. J. Exp. Biol. 89: 117-157.

Kupfermann, I., and K. R. Weiss (1981) Tail-pinch and handling facilitate feeding behavior in Aplysia. Behav. Neural Biol. 32: 388-394.

Lee, K. S. (1982) Sustained enhancement of evoked potentials following brief, high-frequency stimulation of the cerebral cortex in vitro. Brain Res 239: $617-623$

Lee, K. S. (1983) Cooperativity among afferents for the induction of longterm potentiation in the CA1 region of the hippocarmpus. J. Neurosci. 3 : 1369-1372.

Levy, W. B., and O. Steward (1979) Synapses as associative memory elements in the hippocampal formation. Brain Res. 175: 233-245.

Levy, W. B., and O. Steward (1983) Temporal contiguity requirement for long-term associative potentiation/depression in the hippocampus. Neuroscience 8: 791-797.

Livingstone, M. S., P. P. Sziber, and W. G. Quinn (1984) Loss of calcium/ calmodulin responsiveness in adenylate cyclase of rutabaga, a Drosophila learning mutant. Cell 37: 205-215.

Lynch, G., and M. Baudry (1984) The biochemistry of memory: A new and specific hypothesis. Science 224: 1057-1063.

McNaughton, B. L. (1983) Activity dependent modulation of hippocampal synaptic efficacy: Some implications for memory processes. In Neurobioogy of the Hippocampus, W. Siefert, ed., pp. 233-252, Academic Press, London.

McNaughton, B. L., R. M. Douglas, and G. V. Goddard (1978) Synaptic enhancement in fascia dentata: Cooperativity among coactive afferents. Brain Res. 157: 277-293.

Neuman, R. S., and C. W. Harley (1983) Long-lasting potentiation of the dentate gyrus population spike by norepinephrine. Brain Res. 273: 162165.

Ocorr, K. A., E. T. Walters, and J. H. Byrne (1983) Associative conditioning analog in Aplysia tail sensory neurons selectively increases cAMP content. Soc. Neurosci. Abstr. 9: 169.

Ocorr, K. A., E. T. Walters, and J. H. Byrne (1985) Associative conditioning analog selectively increases CAMP levels of tail sensory neurons in Aplysia. Proc. Natl. Acad. Sci. U. S. A., in press.

Pinsker, H. M., W. A. Hening, T. J. Carew, and E. R. Kandel (1973) Longterm sensitization of a defensive withdrawal reflex in Aplysia. Science 182. 1039-1042.

Pollock, J. D. J. S. Camardo, L. Bernier, J. H. Schwartz, and E. R. Kandel (1982) Pleural sensory neurons in Aplysia: A new preparation for studying the biochemistry and biophysics of serotonin modulation of $\mathrm{K}^{+}$currents. Soc. Neurosci. Abstr. 8: 523

Racine, R. J., N. W. Milgram, and S. Hafner (1983) Long-term potentiation phenomena in the rat limbic forebrain. Brain Res. 260: 217-231.

Robinson, G. B., and R. J. Racine (1982) Heterosynaptic interactions between septal and entorhinal inputs to the dentate gyrus: Long-term potentiation effects. Brain Res. 249: 162-166.

Schwartzkroin, P. A., and K. Wester (1975) Long-lasting facilitation of a synaptic potential following tetanization in the in vitro hippocampal slice. Brain Res. 89: 107-119.

Swanson, L. W., T. J. Teyler, and R. F. Thompson (1982) Hippocampal longterm potentiation: Mechanisms and implications for memory. Neurosci. Res. Program Bull. 20: 613-769.

Walsh, J. P., and J. H. Byrne (1984) Forskolin mimics and blocks a serotoninsensitive decreased $\mathrm{K}^{+}$conductance in tail sensory neurons of Aplysia. Neurosci. Lett., in press.

Walters, E. T. (1980) Sensitization and classical conditioning in Aplysia: Behavioral and neuronal studies. Doctoral dissertation (unpublished), Columbia University, New York.

Walters, E. T., and J. H. Byrne (1983a) Associative conditioning of single sensory neurons suggests a cellular mechanism for learning. Science 219: 405-408.

Walters, E. T., and J. H. Byrne (1983b) Slow depolarization produced by associative conditioning of Aplysia sensory neurons may enhance $\mathrm{Ca}^{2+}$ entry. Brain Res. 280: 165-168.

Walters, E. T., and J. H. Byrne (1983c) Long-term potentiation, activitydependent neuromodulation, and associative information storage in Aplysia. Soc. Neurosci. Abstr. 9: 168.

Walters, E. T., and J. H. Byrne (1984) Post-tetanic potentiation in Aplysia sensory neurons. Brain Res. 293: 377-380.

Walters, E. T., T. J. Carew, and E. R. Kandel (1979) Associative learning in Aplysia californica. Proc. Natt. Acad. Sci. U. S. A. 76: 6675-6679.

Walters, E. T., T. J. Carew, and E. R. Kandel (1981) Associative learning in Aplysia: Evidence for conditioned fear in an invertebrate. Science 211. 504-506.

Walters, E. T., J. H. Byrne, T. J. Carew, and E. R. Kandel (1983a) Mechanoafferent neurons innervating the tail of Aplysia. I. Response properties and synaptic connections. J. Neurophysiol. 50: 1522-1542.

Walters, E. T., J. H. Byrne, T. J. Carew, and E. R. Kandel (1983b) Mechanoafferent neurons innervating the tail of Aplysia. II. Modulation by sensitiz ing stimulation. J. Neurophysiol. 50: 1543-1559.

Yamamoto, C., and T. Chujo (1978). Long-term potentiation in thin hippocam pal sections studied by intracellular and extracellular recordings. Exp. Neurol. 58: 242-250. 